\title{
LA FUERZA DEL RAYO DENTRO DEL PROCESO CÓSMICO DE LOS MAYAS DE MESOAMÉRICA Y EL MÉXICO CONTEMPORÁNEO
}

\author{
Gustavo Aviña Cerecer
}

Instituto de Investigaciones Antropológicas, unıM

\begin{abstract}
Aвstract: The god $\mathrm{K}$ (according to the Schellhas clasification), as all the major gods of the ancient Mayan, was an important part of the great process of life and death. And, in some way, still does. In this sense, this god symbolizes a lot of relationships between diferents elements of the Maya cosmology. But in all of this variability, there's a structural meaning, that stills along of all the time and space of Mesoamerica. This article proposses that this meaning is the force that breaks the "hard part" of the materials of life to extract from them, their "spiritual part"; and how, trough the arqueological and ethnography data, this function appears in the Mayan society.
\end{abstract}

Resumen: El dios K (de acuerdo con la clasificación de Schellhas), como todos los grandes dioses mesoamericanos, representaba una parte importante del proceso de vida y muerte y, de hecho, en alguna medida, lo sigue haciendo. En este sentido, el dios $\mathrm{K}$ da cuenta de múltiples relaciones cósmicas. Pero, aun por encima de todas sus manifestaciones variables, hay un gran significado estructural que permite la posibilidad de sus múltiples valores. En este artículo se propone que este significado estructural es la fuerza que rompe la "parte dura" de las cosas, para liberar "la materia sutil" de lo divino, y se explica cómo, a través de evidencias arqueológicas y etnográficas, esta función aparece en la sociedad maya.

His name is Thunder! His love is fire!

$\mathrm{He}$ is the flame and the fury!

Viva Zapata!

The name of a man ....

with the heart of a tiger!

The San Diego Union, San Diego, marzo 14 de 1952

Introducción

1

Los mayas, sin duda, tienen una gran riqueza creadora e imaginativa. Su enorme historia mítica se reproduce en múltiples prácticas y objetos. El rayo es uno de los elementos más importantes de su pensamiento, $\mathrm{y}$ aunque es un fenómeno natural, ha sido percibido por su fantástica visión de manera totémica (Lévi-Strauss, 1986).

Todo en el mundo maya, las plantas, los animales, las estrellas, las piedras, las personas, en fin, todo el ámbito de su percepción está constituido por seres que son producto de poderes divinos. En este sentido, es un universo básicamente religioso, donde es enorme la cantidad de prácticas, socialmente determinadas, con las que se puede lograr el extásis trascendental y que llevan a los hombres al contacto con los dioses y, por ende, a percibirse como parte de un todo cósmico. 
Esta noción de totalidad experimentada mediante el éxtasis es percibida por el maya al reconocerse como parte de un universo circular, completo y cerrado en el que lo nuevo inmediatamente es ubicado dentro de su mundo; no hay lugar para la excentricidad. Cualquier acontecimiento, por extraño que parezca, el maya inmediatamente lo refuncionaliza dentro de su propia percepción del mundo y en la medida en que la tradición subsiste, su mundo y sus dioses también existen. ${ }^{1}$

Asimismo, es un universo concebido de manera total, porque la reflexión humana actúa aún en las regiones metafisicas y en los momentos post-mortem.

El universo maya es también una totalidad en el sentido estructural y dialéctico de la palabra, ${ }^{2}$ es decir que es un enorme sistema de relaciones significativas con las que de manera consciente y práctica (histórica) e inconsciente y lógica (estructural) se ordena un mundo.

Estas tres cuestiones: la experiencia religiosa del ser en el cosmos, la conceptualización de todo un ciclo de vida completo, cerrado, y la coherencia lógica y práctica de la vida, son, como en el caso de todas las grandes culturas, intentos constantes que nunca llegan a ser un logro consumado. En este sentido, antes que nada, por conveniencia heurística y metodológica, se debe concebir a "Rayo" 3 como un antiguo intento ideológico y práctico del hombre ante un portentoso universo poblado de fuerzas desconocidas (Garza, 1990).

La cultura de los mayas es la expresión de un universo que de manera "natural", pero divi- na, retó a los hombres a comprender, a trabajar y a comunicarse dentro de una tierra recientemente domesticada.

Con el exterminio de los mayas no se pierde a un campesino que de sol a sol trabaja la tierra negándose a dejar enterrado su pasado; tampoco se pierde a un indígena exótico que merece un lugar en los museos y en los tianguis; se pierde parte de la conciencia histórica de los hombres, aquella del tiempo en que la tierra era un enorme ser femenino apenas domesticado, en la cual todos los hombres, por sus relaciones de poder con la sangre, eran dioses y podían alcanzar la experiencia trascendental de la totalidad.

Es por esto que el conocimiento del cosmos de los mayas puede llegar a ser un saber muy apreciado para nosotros, personas de la modernidad, que hemos olvidado toda mediación ideológica entre el hombre y el medio natural.

Ahora la tierra es trabajada y sobreexplotada, sin impedimento alguno, salvo las reglas de acumulación de capital. Los dioses han muerto y con ellos se ha ido el antiguo diálogo del hombre con lo que a simple vista se aprecia como más poderoso que él: la naturaleza y las fuerzas que le dan vida.

\section{II}

En este trabajo consideramos a los dioses como los subsistemas integrantes de la estructura universal de los mayas de mayor nivel de complejidad. "Rayo" es un dios, es decir que es uno de estos grandes subsistemas ideológico-prácticos

\footnotetext{
${ }^{1}$ Las particularidades de las sociedades mesoamericanas se pueden equiparar con las que apunta LéviStrauss (1992, pp. 66-72) como características de las sociedades estudiadas por los etnólogos; son las mismas características de la cosmovisión que posibilitan lo que Alfredo López Austin (comunicación personal en noviembre de 1993) alguna vez denominó procesos históricos de refuncionalización.

${ }^{2}$ El concepto de totalidad está tomado de Karel Kosik, 1982; y los de estructura y dialéctica se han tomado principalmente de la obra de Lévi-Strauss, 1984.

${ }^{3}$ Apuntamos el nombre de "Rayo" como nombre personal para referirnos a una fuerza anímica que sobrepasa por mucho la simple presencia atmosférica
Estudios de Cultura Maya. Vol. XX1,2000

Instituto de Investigaciones Filológicas/

Centro de Estudios Mayas, UNAM

ISSN: 0185-2574
} 
de relaciones significativas dentro del ámbito de acción de los mayas. Su conceptualización es el resultado de una reflexión práctica que ha logrado la conjunción de lo diverso.

En este sentido, el significado de alguno de los dioses mayas incluye distintas relaciones ideológicas y prácticas sociales de muy diverso orden y complejidad. De acuerdo con esto es que se puede entender lo fantástico del pensamiento maya, pues lo fantástico no es más que la expresión de un ejercicio lógico de abstracción que une de manera coherente lo múltiple y lo diverso.

Asimismo, "Rayo", como todo dios, es un subsistema de relaciones que de manera lógica y racional está dentro de distintos ámbitos del universo en el que se halla inmerso. Su inmenso poder abstracto no impide que aparezca hasta en los más simples e insignificantes detalles de la vida o que, de igual manera, también se le tenga que incluir cuando se hace referencia a una instancia superior como la de los dioses creadores. De tal manera que, con cada dios estamos tratando con un subsistema abierto, capaz de conjugarse dentro de otros ámbitos y de incluir a muchos otros dentro de su contenido.

De hecho, los elementos del pensamiento humano no son "objetos" cerrados o piezas de un rompecabezas, sustituibles entre sí mediante palabras; son unidades abiertas de conjugación significativa, capaces de amoldarse en muy diversas situaciones culturales y de conformar el significado de muchos otros elementos y situaciones.
En este sentido estamos lejos de las escuelas de pensamiento - principalmente la norteamericana- que pretenden la identificación de un dios, mediante definiciones nominales; pensamos más bien en la búsqueda de relaciones que se puedan conjugar dentro de los diversos ámbitos de la acción social.

Ciertamente es más simple y rápido conformar un rompecabezas de elementos nominales divinos y, según criterios subjetivos de similitud formal, realizar diversos modelos estáticos o "paisajes cósmicos", pero he preferido alejarme de esta posición reduccionista que emplea una teoría funcionalista en combinación con el concepto más simple de sistema. ${ }^{4}$

El significado es el "uso en sociedad" de los contenidos significativos de los sistemas ideológi$\cos .^{5}$ En este sentido, aquí presentamos a "Rayo" como significado dentro de algunas de las situaciones ideológico-prácticas, culturalmente determinadas por los mayas.

Veremos cómo "Rayo", en su papel de dios, relaciona de manera lógica la personalidad de un ser fantástico divino, una fuerza casi invisible, un fenómeno natural, un instrumento del sacrificio, un instrumento de trabajo, un arma de guerra, una personalidad humana y un símbolo de poder mágico.

III

La analogía ha sido nuestra principal brújula dentro del mar de figuras, relatos y objetos que

\footnotetext{
${ }^{4}$ Quienes trabajan con este marco teórico piensan que sistema es un conjunto de elementos relacionados entre sí, de tal manera que sus contenidos semánticos tienen un significado predeterminado por su representación formal y una función. Dicha epistemología es la que básicamente usan en la Escuela Norteamericana de Epigrafia.

s Además de la propuesta lingüistica de Ferdinand de Saussure, donde significado=imagen y significante=palabra, hay otras formas de concebir al lenguaje y en general al sistema de composición de los símbolos, aquí nos interesan particularmente propuestas fenomenológicas como la de Wittgenstein, para quien el significado no es algo estático sino acción en sociedad, y la palabra es tan sólo una técnica que refiere a dicho conjunto de prácticas culturales. Véase, por ejemplo, Ludwig Wittgenstein, 1997.
} 
hemos estudiado. Aunque esta herramienta metodológica ya ha probado su efectividad en varios estudios de la cosmovisión mesoamericana, cabe tener en cuenta los requisitos apuntados por varios investigadores para lograr una mayor plausibilidad en los resultados (Ascher, 1961, p. 324). Estos requisitos son: 1. buscar analogías entre culturas que manipulan ambientes parecidos de manera similar; 2. seleccionar sociedades que tengan el mismo nivel tecnológico; y 3. considerar la distancia espacio-temporal entre las culturas que se están comparando.

En esta investigación se cumplen estos requerimientos; de hecho, en estos casos, en los que se realizan analogías entre Mesoamérica y las mismas sociedades indígenas posteriores a la conquista, se superan por mucho estos requisitos, pues se está tratando de una superárea de continuidad tecnoambiental, económica y social.

Así, en el caso del estudio antropológico de México, no se presenta una cuestión de encontrar conexiones entre un pasado muerto y un presente vivo, sino de un estudio de continuidad bistórica. Sin embargo, de ninguna manera se pueden establecer equiparaciones de identidad entre las sociedades antiguas, las posteriores a la conquista y las de nuestros días. Hay que tomar en cuenta las múltiples diferencias de orden biológico y social que son consecuencia del devenir histórico, así como las provocadas por la variabilidad espacial, y esto se ha de considerar ya sea en un análisis sincrónico o en uno diacrónico.

Finalmente, hay otro nivel variable que se ha considerado al momento de usar las analogías: la variabilidad lógico-estructural que se da dentro de la misma sociedad estudiada, es decir, a las distintas formas en que los mayas relacionaban lo análogo o similar dentro de su mundo. Por ejemplo, es verdad que "Rayo" y el sol son similares, pero esto no quiere decir que son totalmente lo mismo o que exista una identidad
Estudios de Cultura Maya. Vol. XXI,2000

Instituto de Investigaciones Filológicas/

Centro de Estudios Mayas, UNAM

ISSN: 0185-2574 entre ambos elementos; sí se identifican pero no son idénticos, hay que encontrar el sentido más plausible en que son similares y la razón de dicha similitud.

\section{IV}

En concordancia con estas cuestiones teóricas y metodológicas, se habla de "Rayo" como de un dios prehispánico o de un santo contemporáneo; sin embargo, dejaremos en claro datos que no sólo permiten encontrar similitudes sino también diferencias.

Cabe destacar que el presentar la continuidad tradicional de "Rayo" en este artículo, no es lo más importante, sino que con las relaciones sociales encontradas hemos intentado destacar un proceso ideológico que pensamos estructural y por ende de una fuerte resistencia al cambio cultural.

Se trata de ver a "Rayo" como un elemento ideológico que se transforma en el tiempo, únicamente como un primer paso para la realización de una abstracción de mayor nivel, en la que se corrobora a "Rayo" como un conjunto de relaciones que dan cuenta de un proceso ideológico, capaz de otorgar orden al mundo de los mayas.

Entonces, "Rayo" incluye dentro de su ámbito de poder múltiples circunstancias con una gran diversidad de elementos, para derivar en la representación divina de un proceso, que en la mente de los mayas se presenta como inmanente al devenir del tiempo universal.

\section{El dios K y "Rayo"}

Hace más de noventa años, en 1904, P. Schellhas, estudiando el Códice de Dresde y basado en semejanzas y diferencias gráficas, diferenció 15 dei- 
dades mayas, nombrándolas con algunas de las letras del abecedario, de la A a la P.

Al dios de la letra $\mathrm{K}$, lo identificó como aquel de la larga nariz onarmentada con forma probósica y por simple similitud formal (Taube, 1992, pp. 78-80) lo relacionó con el dios $\mathrm{B}$, equivalente al dios Chaak yucateco: "Dios de los panes, el agua, de los truenos y el relámpago". 6

Dos años después Förstemann da cuenta de que el dios $\mathrm{K}$, aun cuando comparte características del dios B, es un tipo de especialización de éste, y con base en datos etnográficos afirma que: "su nariz ornamental en Centroamérica, de acuerdo con un convencionalismo, pretende representar al relámpago de la tormenta" (Robicsek, 1979, pp. 111-128).

Por otro lado, E. Seler, en 1903, también estudiando el Códice de Dresde llegó a la conclusión de que el dios que Schellhas identificó como dios K, era uno de los cuatro Bacabo'ob: sostenedores del mundo o regentes de las regiones y los años mayas, identificado en la obra de fray Diego de Landa con el nombre de Bolon Dz'akab.

Esta identificación del rayo en el plano del tiempo y el espacio, realizada por Seler, se corrobora en los libros del Chilam Balam porque el mismo regente del año, correspondiente a la región espacial del sureste, en este texto se llama Cauac, término que significa: "rayo o relámpago".

Diez años después, H. Spinden, estudioso del arte prehispánico maya, encuentra que el dios $\mathrm{K}$ es la deidad representada en la boca de la cabeza trasera del monstruo bicéfalo y de la barra ceremonial, identificación que además, permite establecer una similitud entre el monstruo bicéfalo y la barra ceremonial.

Spinden señalaría otra identidad de gran importancia para el estudio del dios K y "Rayo"; en ese mismo estudio de 1913 nos dice que otro de los objetos ceremoniales de mayor importancia, el cetro maniquí, tiene el cuerpo entero y la cabeza del dios $\mathrm{K}$, ya que al igual que el dios $\mathrm{B}$, el $\mathrm{K}^{7}$ es de naturaleza serpentina, pero también tiene otra característica importante que es sólo del dios K: un objeto que está atravesando la cabeza del dios, que en el caso del cetro es siempre un hacha.

Spinden también rectificará la propuesta de Maudsley, quien veía al maniquí y a su empuñadura de cuerpo de serpiente como dos entidades separadas, pues él demuestra que todo el cetro, maniquí y la empuñadura de serpiente son un mismo ser fantástico, de tal manera que la empuñadura es una de las piernas del maniquí (Spinden, 1992, p. 51).

De manera general, de estas investigaciones se ha concluido que las tres características distintivas del dios $\mathrm{K}$ son: larga nariz probósica, cabeza atravesada por objetos diversos y pierna que se extiende en forma de cuerpo de serpiente. Las dos primeras caraterísticas son constantes; la última, aunque distintiva, es prescindible (figura 1).

Asimismo, Thompson, en la década de los setenta, mediante un análisis epigráfico estableció una extrapolación del rayo hacia al ámbito temporal, pues en varias claúsulas complementarias de fechas mayas con Cuenta Larga encuentra al Dios $\mathrm{K}^{8}$ Además, con información etnográfica de tzotziles y yucatecos, da cuenta de la re-

\footnotetext{
${ }^{6}$ En este caso, como en todos aquellos donde se han traducido palabras mayas al español, hemos utilizado para el maya-yucateco el Diccionario maya Cordemex; para el tzeltal, el Vocabulario de Lengua Tzeltal, de fray Domingo de Ara, y, para el chol, La lengua chol, de Tila (Chiapas), de Otto Schumann.

${ }^{7}$ Para abundar en el conocimiento de la naturaleza serpentina de estos dioses, véase Garza, 1984.

${ }^{8}$ Esta extrapolación de un fenómeno natural a otros planos de significado, en este caso al del tiempo y al del espacio, es un recurso propio de la lógica mesoamericana. Evon Z. Voght, Alfonso Villa Rojas y Alfredo 


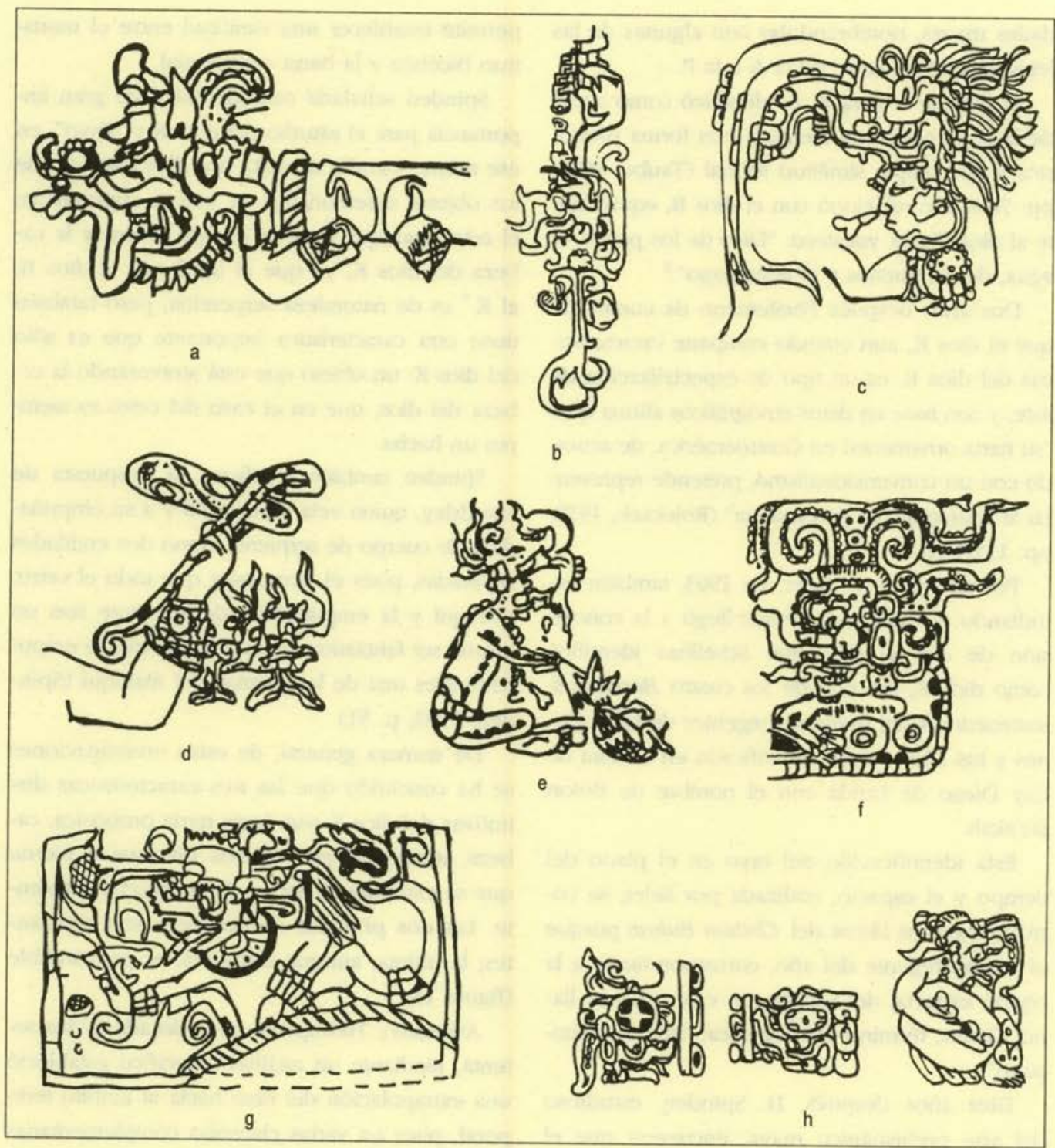

Figura 1: a. Barra ceremonial sostenida por un alto personaje de Tikal; adentro de la boca de la víbora está sentado el dios $K$, con su apéndice serpentino y su hacha en la cabeza (tomado de Spinden, 1992, p. 55). b. Parte posterior de otra barra ceremonial, estela 10 de Seibal (tomado de Spinden, 1992, p. 55). c. Personaje pintado en un vaso funerario del Petén (tomado de Robicsek, 1979, p. 121). d. Hacha con cuerpo de serpiente, que es de un personaje de Palenque (tomado de Schele, 1992, p. 274). e. Dios K de cuerpo entero y su hacha humeante en la frente (tomado de Robicsek, 1979, p. 119). f. Dios K como parte de un monstruo bicéfalo del templo 4 de Tikal (tomado de Thompson, 1987, p. 273). g. Dios $K$ de cuerpo entero, tablero de la Santa Cruz Quiché (tomado de Spinden, 1992, p. 50). h. Distintos ejemplos del dios K con el numeral 9 (tomado 
lación de "Rayo" con el tabaco y, con información de los mopanes, dice que las hachas son "piedras de Rayo" (Thompson, 1987, pp. 144$148,308)$.

Los investigadores del dios $\mathrm{K}$ posteriores a Thompson, de la década de los ochentas hasta la fecha, se han dedicado básicamente a la corroboración de sus características iconográficas y a su identificación con el rayo.

Destaca la polémica que ha surgido en torno a la naturaleza de los objetos que atraviesan su frente. Robicsek, en 1978, propone que hay un objeto principal y los demás son simples variantes; este objeto principal sería un enorme cigarro, por lo que, según él, el dios $\mathrm{K}$ es "el dios fumador" por excelencia. Aunque hay evidencia que permite pensar que en ocasiones el objeto sí es un gran cigarro encendido, no la hay para afirmar que éste es el objeto principal (Aviña Cerecer, 1994, pp. 39-40).

Algunos años después, en 1983, la historiadora del arte, L. Schele, propondrá que la variedad de objetos sostenidos en la cabeza del dios $\mathrm{K}$ son meros aditamentos lingüísticos para asegurar que el dios $\mathrm{K}$ tiene un espejo de obsidiana en la frente. Su propuesta es reduccionista, ya que niega todo el posible contenido simbólico de los distintos materiales que aparecen en la frente de este dios y además es improbable pues no existe evidencia alguna de espejos de obsidiana en el área maya. Sin embargo, contribuye positivamente al escribir que algunos de estos objetos son antorchas de fibra de ocote y de cerámica.

Coggins, en 1988, publica un estudio del dios $\mathrm{K}$ en el que presenta cuatro cetros maniquí encontrados en el cenote sagrado de Chichén Itzá.
Lo interesante de estos objetos es que son incensarios, además de cetros y que sus maniquíes están en una posición descendente. Posición que permite a Coggins relacionar al dios $\mathrm{K}$ con una fuerza celeste y masculina, hecho que ya había planteado en un trabajo anterior de 1977, en el que había destacado que en varias ocasiones este objeto frontal era un hacha y, por tanto, un instrumento masculino y de guerra. Coggins también encontró que en Copán, majestuoso sitio maya del periodo Clásico que está en Honduras, existía una representación de un dios $\mathrm{K}$ con cara de Tlaloc: dios de los cerros y las lluvias de los grupos náhuatl del centro de México, lo que le permite corroborar que el dios $\mathrm{K}$ está haciendo referencia al complejo de fenómenos pluviales (Coggins, 1988, p. 143).

En verdad, la mayoría de los investigadores, salvo Schele, apuntaron sobre esta relación del dios $\mathrm{K}$ con el dios Chaak y, en especial con el rayo; sin embargo, será Taube quien, en 1992, en un estudio sobre los dioses mayas del periodo Posclásico, confirme esta idea con varios ejemplos del área maya y comparativos entre los nahuas y los mayas (figura 2).

Taube también reconoce la íntima relación del dios $\mathrm{K}$ con los espejos, pero no de obsidiana, como apuntaba Schele, sino de pirita. ${ }^{9}$ Para corroborar esto, menciona los espejos de pirita del cenote sagrado de Chichén Itzá, los maniquíes de madera y estuco del entierro 195 de Tikal, así como información etnográfica de los mayas de Yucatán. También reafirma lo ya planteado por Coggins respecto a que el rayo es una Xiuhcoátl, serpiente de fuego, y por tanto, equivalente al atlatl nahua o al hacha maya.

López Austin en distintos estudios han identificado este ejercicio metafórico, nombrándolas sinonimias o réplicas; al respecto véase Aviña Cerecer, 1994, pp. 14-17. Respecto de la participación del dios K en la Cuenta Larga, véase Thompson, 1943.

"Es importante destacar que el espejo es brillante y que es por esta similitud perceptual por la que "Rayo" y el espejo comparten la misma carga anímica. Respecto de la relación de los espejos con el encendido del fuego, las artes mágicas y el rayo, véase Clemency Coggins, 1987, p. 449; Taube, 1992, p. 75, y Aviña Cerecer, 1994. 


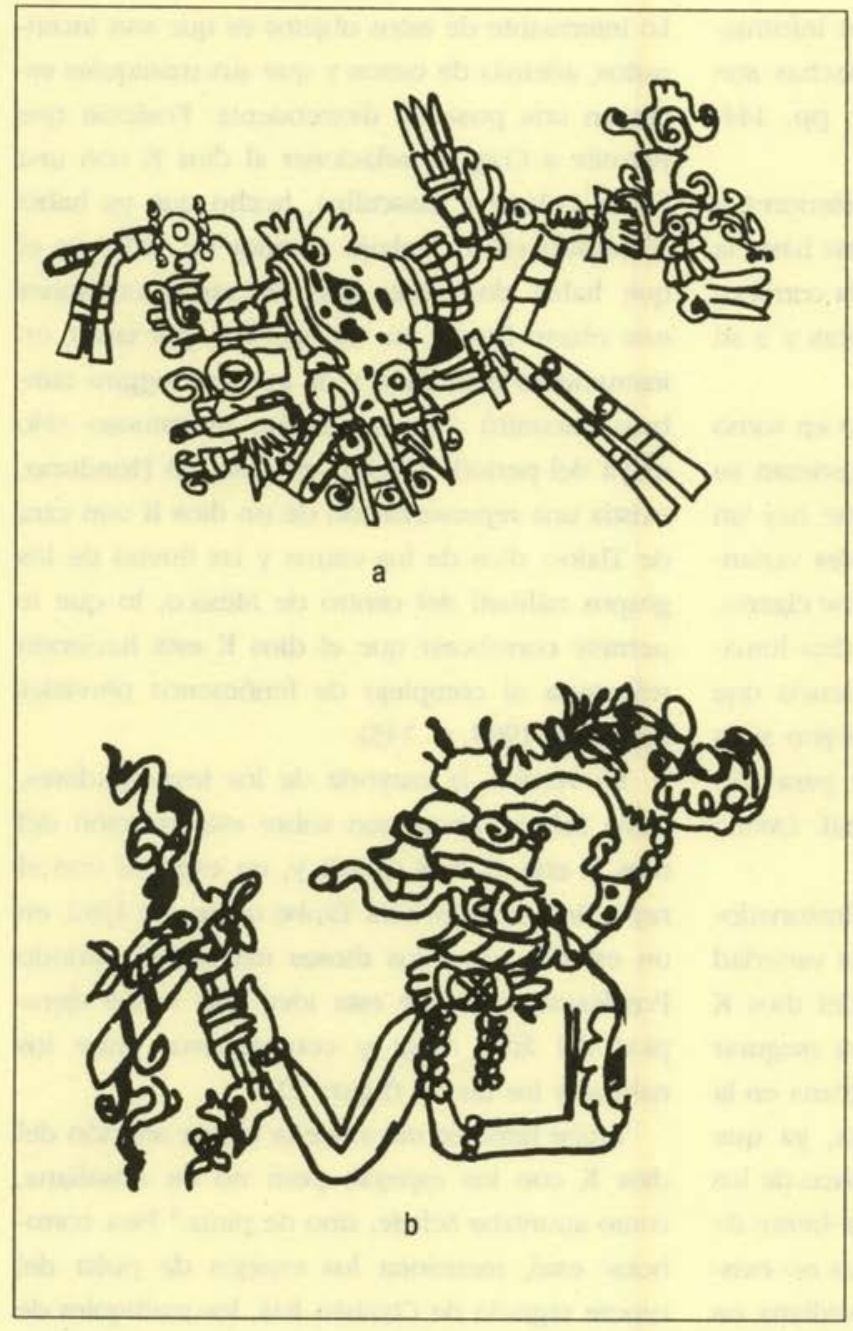

Figura 2. a. Tláloc con hacha de fuego; folio 2 del Códice Laud.

b. Chaak con su hacha de fuego; vaso policromo del Petén (tomado de Taube, 1992, p. 79)
Aquí se piensa que este presupuesto teórico de la identificación elemental de una fuerza divina, en este caso "Rayo", lleva a este tipo de conclusiones que, aunque aclaran el panorama, también lo simplifican quizá demasiado.

Identificar como equivalente la variabilidad de elementos que componen al dios del rayo sólo puede servir como un paso antecedente para la tarea de precisión de las sinonimias que se establecen entre dichos elementos. En este sentido, aunque todos los elementos del dios sean parte de una misma estructura significativa, ciertamente en la estructura del rayo, su significado no es equivalente sino complementario.

Cabe recordar que la lógica fundamental de la abstracción fantástica del pensamiento de los mayas es la analogía, la cual de ninguna manera permite establecer identidades. Además, como a continuación veremos, la sinonimia entre los elementos se establece tanto de manera metafórica como metonímica, es decir que dentro de un mismo campo o en distintos campos de la acción humana se pueden establecer distintas similitudes.

Estas aclaraciones epistemológi-
De hecho, Taube intenta concluir la polémica de la diversidad de objetos que lleva en la frente el dios $\mathrm{K}$, proponiendo que ciertamente este dios se relaciona con el tabaco, con las antorchas de ocote, con los espejos brillantes de pirita y con el hacha, porque todos estos objetos aluden al rayo celeste. Incluso dirá que el pie serpentiforme también debe de aludir al rayo. cas, al tiempo que permiten determinar cuáles son los campos de acción de la fuerza divina "Rayo", permiten establecer las relaciones ideológicas que unen la variabilidad elemental de que se compone, así como a la determinación del proceso natural y divino al que están haciendo referencia dichas relaciones en su conjunto. 


\section{La fuerza divina de "Rayo"} dentro del proceso cósmico maya

\section{La naturaleza caliente de "Rayo"}

Según la cosmovisión de los pueblos mesoamericanos y de los indígenas actuales, toda la materia existente puede incluirse dentro de dos grandes categorías: lo caliente y lo frío (López Austin, 1990, pp. 242-251). Esta dualidad se corresponde con la de lo celeste y lo terrestre, lo masculino y lo femenino. Muchos de los dioses mesoamericanos, y "Rayo" no es la excepción, contienen una naturaleza dominante, aunque esto no les impide participar dentro de procesos de naturaleza contraria. En este caso, la naturaleza dominante de "Rayo" es caliente, celeste y masculina.

En varias representaciones del dios $\mathrm{K}$, éste lleva el símbolo de $K i n$, que quiere decir "sol, día y calor del sol". Navarrete, en 1974, al estudiar la religión de los indios chiapas, ya apuntaba sobre la posible naturaleza solar del rayo. Además, es claro que entre los nahuas el rayo es una emanación solar. Así se puede apreciar en el mito del nacimiento de Huitzilopochtli, dios solar del Sur y joven guerrero, que con una Xiuhcoátl, es decir, una serpiente de fuego o rayo, decapita a su hermana, que es la luna, salvando así a su madre, que es la tierra (León-Portilla, 1984, pp. 77-78). Fernando Ortiz (1984, p. 38), arqueólogo cubano, anota, como dato curioso, que varios grupos aborigenes antillanos creen, al igual que los tezcocanos nahuas del centro de México, que el hombre proviene de un agujero hecho en la tierra por un rayo que fue mandado por el sol.
Hay otro elemento relacionado con "Rayo" que nos permite apreciar aún mejor su naturaleza caliente y solar; nos referimos a la cabeza.

Son muchos los ejemplos en los que aparece de manera aislada la cabeza del dios $\mathrm{K}$; buenas representaciones son los vasos policromos del Posclásico maya de la colección fotografiada por J. Kerr. Además se puede apreciar que en las páginas 2 a 11 del Códice París, se han plasmado las imágenes de personajes importantes que presentan como ofrendas cabezas del dios $\mathrm{K}$ ante otro personaje de mayor alcurnia.

Asimismo, es bastante clara la relación del dios $\mathrm{K}$ con el sacrificio por decapitación. Así se puede apreciar en el vaso policromo 1 de la colección privada de $\mathrm{M}$. Coe y en la pilastra $\mathrm{F}$ de la casa D del Palacio de Palenque. También está el hecho de que es con el instrumento de "Rayo", el hacha, con el que se realiza la decapitación.

Además, en varios ejemplos del cetro maniquí, es decir, el hacha con cuerpo de dios $\mathrm{K}$, se ha representado la cabeza de sots, el murciélago, animal relacionado en toda Mesoamérica con la decapitación. ${ }^{10}$ Todo esto apunta sobre la íntima relación del dios K o "Rayo" con la cabeza, la cual viene a reafirmar lo arriba apuntado sobre la naturaleza solar del rayo, porque es justamente en la cabeza donde se encuentra la "carga anímica" solar conocida entre los nahuas como tonalli y entre los mayas yucatecos como kinal. ${ }^{11}$

Estas "cargas" son similares no sólo porque ambas comparten la naturaleza caliente del sol, sino también porque ambas se encuentran en la cabeza y se les relaciona con la memoria, la bondad, la valentía, la fuerza del crecimiento y el poder del guerrero y el brujo.

\footnotetext{
${ }^{10}$ Algunos de tantos ejemplos aparecen en la estela D y el altar T de Copán; en la cabeza trasera de la barra ceremonial de la estela 11 de Ceibal; en el cetro maniquí de la estela 1 de Jimbal; así como en la columna 17 del Templo de los Guerreros de Chichén Itzá. Véase Gustavo Aviña Cerecer, 1994.

${ }^{11}$ La información más completa sobre el tonalli está en Alfredo López Austin, 1989, pp. 223-250; Alfredo Villa Rojas (1985, p. 190) identifica al kinal entre los mayas como algo similar al tonalli.
} 
Así, todo el complejo ritual de la decapitación es básicamente solar: el arma en el ritual de decapitación es el hacha, la cual también tiene la carga del rayo caliente, la ofrenda es la cabeza que también tiene carga solar, pero además el hombre que decapita, es decir, el funcionario gubernamental que empuña el hacha, debe tener una gran cantidad de calor corporal (figuras 3 y 4 ).

En toda Mesoamérica se pensaba que este calor corporal aumentaba conforme pasaban los años, pero también, por la disciplina militar o los poderes de brujería que tuviera el hombre (López Austin, 1989; Aviña Cerecer, 1994).

Otro complejo social estructurado con base en el calor es el de las labores agrícolas en la milpa. Las actividades viriles del trabajo de la tierra son, por antonomasia, el deshierbe y la quema del terreno, mismas actividades que realiza el hombre sin la presencia de la mujer, con la ayuda del hacha y cuando el sol está más caliente y poderoso que nunca, es decir, entre los meses de diciembre, enero y febrero. De hecho, lo más conveniente es prenderle fuego al terreno cuando el Sol está en el cenit o poco antes de éste, ya que es en la posición central celeste cuando hace más calor.

La importancia del calentamiento de la milpa es crucial, pues sólo sin rastro alguno de vida vegetal y humedad puede la lluvia cumplir su cometido de fertilización del campo sembrado. Esta especie de supeditación de las actividades calientes a la de la fertilización de la tierra por medio de la lluvia también se encuentra en la estructura del sacrificio por decapitación, ya que es patente que con este tipo de ofrendas cefálicas se espera calentar el ambiente, con el fin de que las lluvias y otras actividades frías puedan cumplir su cometido dentro del proceso cósmico de la vida. Entonces, si bien "Rayo" es caliente, su función no se detiene dentro de esta naturaleza, sino que sólo en su participación dentro del proceso frío de la lluvia su presencia obtiene sentido. A continuación veremos cómo "Rayo" confirma este lugar de ser mediador entre ambas cargas principales y cómo este mismo papel de mediador es el que determina su posición dentro del enorme proceso cósmico de la vida.

\section{La fuerza cortante y liberadora de "Rayo"}

Entre los habitantes de Mesoamérica se concibe que en el universo circulan fuerzas calientes y frías, en forma tanto vertical como horizontal. Un símbolo que hace referencia a tal hecho son los llamados "árboles cósmicos", ${ }^{12}$ que en las cuatro esquinas cósmicas se yerguen como ceibas enormes -en el caso de los mayas-, conectando al cielo con la tierra.

Dentro de estos árboles se supone que circula la materia esencial para la vida e invisible para el común de las personas. López Austin (1990, p. 178) da cuenta de esta concepción de lo contenido esencial dentro de otra materia; lo que deriva en una diferencia entre "la materia dura" que cubre al árbol y "la materia ligera" contenida. Ejemplos de esto son el tablero del Templo de la Cruz, de la Cruz Foliada de Palenque; y de otra zona mesoamericana está la lámina 28 del Códice Fejérvary-Mayer, el folio 19 del Códice Borgia y la lámina 69 del Vaticano $B$ (figuras 5 y 6 ).

Estructuralmente se ha encontrado que "Rayo" está en el hacha, en los cuchillos de pedernal, en el cetro maniquí, en el garrote curvo en las estelas 3, 4 y 9 de Izapa, así como en otras partes de Mesoamérica, los murales pintados del Tlalocan teotihuacano, donde los tlaloque sostienen unos garrotes curvos, el atlatl de los grupos toltecas, los garrotes con obsidiana incrustrada entre los nahuas del Posclásico; e incluso

\footnotetext{
12 Acerca de los árboles cósmicos, véase López Austin, 1993.

Estudios de Cultura Maya. Vol. XXI, 2000

Instituto de Investigaciones Filológicas/

Centro de Estudios Mayas, UNAM

ISSN: 0185-2574
} 


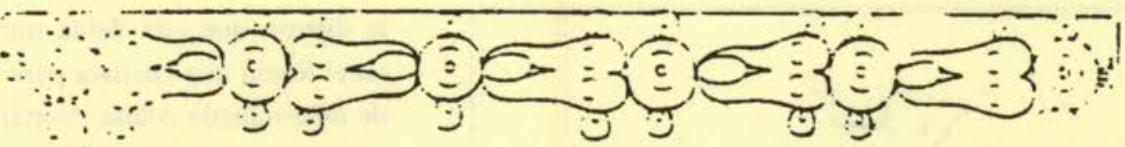

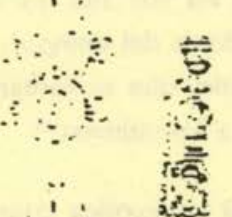
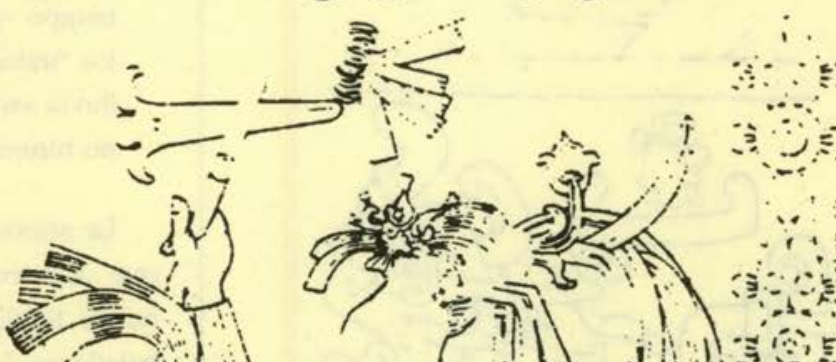

舟

-

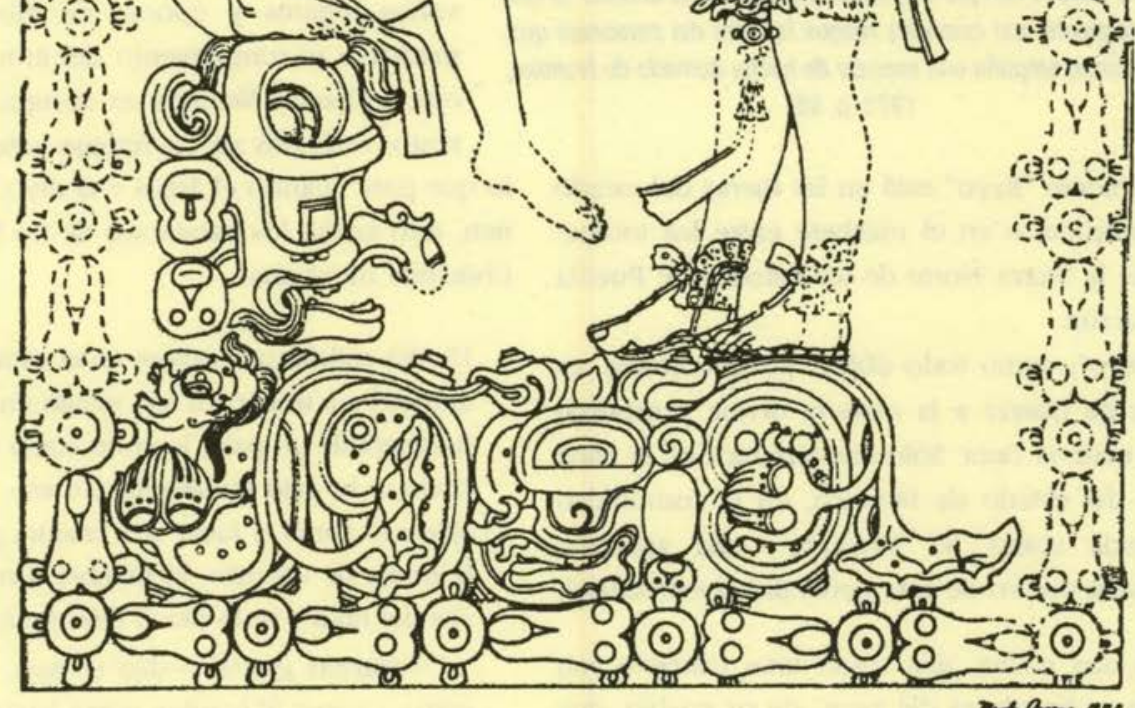

Figura 3. Escultura mural de la pilastra $F$ de la casa $D$ en Palenque (Greene, 1985, fig. 222) 


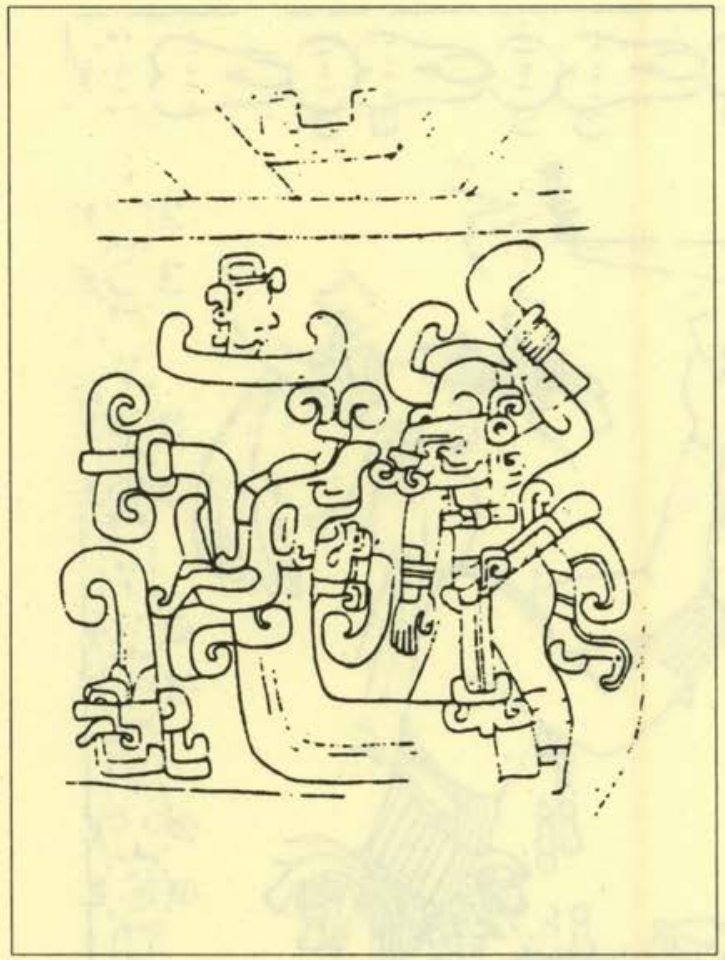

Figura 4. Estela 3 de Izapa en la que según Miller se ha registrado el primer dios $K$ con pie serpentiforme. Nótese la enorme lengua de la serpiente, asi como los rasgos faciales del personaje que, amenazante, empuña una especie de hacha (tomado de Norman, 1973, p. 95)

actualmiente "Rayo" está en las tijeras del estado de Tampico, o en el machete entre los totonacos de la Sierra Norte de los estados de Puebla y Veracruz.

"Rayo", como todo objeto punzocortante, es capaz de liberar a la materia divina y esencial de la materia dura. Sólo encontramos en la zona norte del estado de Morelos, en la comunidad conocida como "El Vigilante", una aparente anomalía dentro de esta generalidad estructural:

En una noche, una mujer tuvo contacto con "los trabajadores del agua" de su pueblo, que le dijeron que ella debía tomar de la olla en el fogón una cuchara para con ella, desde determinada colina, "cortar al viento", al tiempo que en voz alta les debía pedir a los "trabajadores del tiempo", que traían la lluvia volando, que se fueran de allí, que no hirieran a los cultivos. ${ }^{13}$

La anomalía se explica cuando sabemos que aun cuando la mujer, dona Pragedis, nunca había participado junto con los "trabajadores de la lluvia", decide intervenir con sus propios instrumentos femeninos: los de la cocina, y lo hace conservando la letalidad de la materia dura caliente, pues sin duda la cuchara caliente puede ser suficiente para quemar o "herir" a los trabajadores del tiempo, cortando el aire para convencerlos de irse. Más abajo se retomará esta idea de herir en pos de un fin vital.

Lograr la obtención de un don que está en la tierra pero contenido dentro de algo mediante el rompimiento de una capa que impide su liberación se ha simbolizado en varios lugares y épocas de Mesoamérica, mediante el rompimiento del árbol cósmico con un hacha. Veamos un ejemplo de los ya tantos referidos en un trabajo anterior sobre lo que pasa cuando el árbol y el rayo se relacionan, esto según los habitantes de un lugar de la Chinantla mexicana:

Un día andaba un hombre en el campo cuando empezó a a tronar. En eso estalló un rayo en la horqueta de un palo, lo cortó como si fuera un hacha y lo dejó humeando. En eso, el rayo se apareció como si fuera una criatura güera. Con la punta de un palo, el hombre recogió el hacha del rayo y se lo dio al niño (güero).

-Muchas gracias - dijo el rayo, y luego le gritó-: ¡corre! El hombre corrió hacia el pueblo

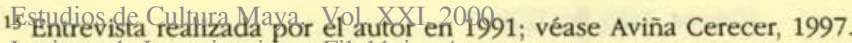

Instituto de Investigaciones Filológicas/

Centro de Estudios Mayas, UNAM 
pájaros carpinteros (son pájaros pequeños que sólo con su pico hacen agujeros en los árboles) uno viejo y otro joven y cuando llegaron les ordenó que sacaran el maíz de la piedra. El pájaro carpintero chico lo intentó pero no pudo... Nuestro Señor llamó al pájaro carpintero viejo y pasó lo mismo. [Pero] Este pájaro carpintero viejo le suplicó a Nuestro Señor le envolviera la cabeza en un trapo rojo y que le compusiera el pico. Nuestro Señor lo hizo poniéndole acero en el pico. Con esto el pájaro agujeró la roca y el maíz comenzó a salir (Hermitte, 1970: 29).

Como vemos, este relato muestra la misma estructura que muchos otros. Es un hombre que tiene hambre y pide, en este caso a Dios, que lo ayude en su desgracia; dios acude en su auxilio pero el maíz está dentro de una piedra muy grande, sólo lo puede sacar con la ayuda de un pájaro con pico de acero, es decir, una entidad celeste con la máxima dureza posible. De hecho, éste es el sentido más claro de la relación entre el "Rayo" y el hacha.

Pero esta capa no sólo es de materia dura rocosa, sino que es también cualquier mediación que esté negando la liberación de un don divino. Así, se puede apreciar la razón lógica de por qué el curandero corta y saca la sangre, por qué los brujos también sacan de otro lado el alma perdida, por qué el cortar en el sacrificio, por qué es igual el penetrar a la tierra con la coa que a la mujer con el pene.

Esto lo podemos corroborar con el análisis etimológico de algunas palabras homófonas y cognadas mayas que hacen referencia al dios de la lluvia, los panes y los cerros, es decir, a Chaak.

En yucateco ch'ak significa "cortar con golpe, con hacha u otro instrumento" y chak es un superlativo, que también quiere decir: "atravesar y hervir", pero además en conjunción con la partícula luké = tierra, es decir, chakluké significa: "atolladero de lodo espeso y profundo", esto es, una cavidad en la tierra. En tzeltal se, mantiene el

Instituto de Investigaciones Filológicas/

Centro de Estudios Mayas, UNAM

ISSN: 0185-2574 mismo sentido, pues chac también se traduce como "abrir".

En la profecía del katún 11 abau del Chilam Balam de Chumayel, Cangel ha sido traducido por Barrera Vásquez como "serpiente de vida", por Roys como "insignia" y por Thompson como "facultades de la vida y el rayo".

Es interesante cómo sin duda estos conceptos hacen referencia al cetro maniquí, pues este objeto, además de ser el hacha-"Rayo", es también una insignia con forma de serpiente de vida que significa que su poseedor tiene las facultades de la vida y el rayo.

Pero aún es más interesante cuando vemos que en el mismo katún 11 ahau, después de que los Bolintiku, los nueve dioses del inframundo, han despojado a los Oxlabuntiku, los 13 dioses del cielo, de su Cangel, dice:

También se llevaron habas, nuestro pan diario molido (maíz), los corazones de semillitas de calabaza, grandes semillas molidas de la calabaza, ça (sic), frijoles molidos. El Bolon Dz'akab Verde envolvió en un paño las semillas (Thompson, 1987: 342).

López Austin ha encontrado que en diversas partes de Mesomérica se hacé referencia a la materia divina esencial que es sutil, mediante el símbolo de las semillas y los corazones de las cosas. Esta profecía del 11 Ahau es otro ejemplo -igual sucede en algunos mitos nahuas prehispánicos- en el que se hace referencia a todas estas semillas de vida por medio de cuatro tipos representativos de cada uno de los colores y regiones cardinales.

Es importante destacar que en este pasaje se demuestra cómo Bolon Dz'akab no sólo interviene en el proceso de la vida sacando las semillas vitales de los cuatro rumbos, sino también reteniéndolas dentro de algo, en este caso dentro de un paño. 
De hecho, esta advocación de "Rayo", Bolon Dz'akab, la podemos traducir, según el diccionario Cordemex, de la siguiente manera: Bolon $=$ "supremo, excelso, nueve"; $D z ' a k=$ "para siempre, aumentar, añadir, multiplicarse", pero también "medicina, jarabe, cura, remedio, exorcismo" y $a b$ es un sufijo verbal, pasivo/activo, entonces Bolon $D z$ 'akab literalmente significa: "Supremo multiplicador brujo o extractor divino" y por la partícula $a b$ se aclara que la acción verbal de $D z^{\prime} a k$ puede ser activa o pasiva, es decir, que participa en el proceso vital ya sea de manera activa: multiplicando, añadiendo, curando, mediante la liberación, la extracción (exorcizando) o de manera pasiva: escondiendo, guardando, ocultando, enfermando.

Bolon Dz'akab Verde dice el Chilam Balam; este color nuevamente nos remite a una posición central dentro del cosmos maya y viene a corroborar lo dicho en otros mitos contemporáneos de los choles y los lacandones, respecto a que es verde el color del rayo de vida. ${ }^{14}$

Lo mismo se dice en el mito prehispánico escrito con caracteres latinos, el Popol Vuh. En este texto, los dioses creadores dijeron a sus comunidades humanas que para poder vivir:

-Decid, pues, nuestros nombres, alabadnos a nosotros, vuestra madre, vuestro padre. ¡Invocad, pues, a Hurakán (una pierna), Chipi Caculhá (Rayo pequeño), Raxa Caculhá (Rayo Verde)... (Popol Vub: 26)

Nótese cómo en esta cita se aclara que los creadores utilizan como mediador entre ellos y los hombres a la trilogía de Hurakán-"Rayo" pequeño-"Rayo verde". En todo el Popol Vub se aclara este papel de mediación de "Rayo"; en este sentido, el hombre logra el contacto con los dioses creadores de la vida mediante el poder de
"Rayo", que, tal como lo hacen los tlaloques (rompiendo las ollas del agua), rompe toda mediación para lograr el aumento, el multiplicar de las materias, liberando así lo que permanece dentro y que es esencial: el corazón, las semillas de la vida.

Incluso este papel de "Rayo" de ser mediador entre lo invisible y lo visible, entre la enfermedad y la cura, entre lo cotidiano y lo mágico, se puede entender como una mediación entre lo caliente y lo frío, lo seco y lo húmedo. Esto se corrobora en la siguiente narración de la Chinantla, donde se expresa que esta penetración de lo caliente en lo frío resulta de la acción de "Rayo":

Se fue un paisano de Usila a Valle Nacional. Cuando llegó a la cumbre del Cerro del Caracol oyó un grito en el monte... El paisano contestó: ¿Quién es el que me llama? "Soy yo, somos amigos", dijo el rayo. Entonces, el paisano vio que el rayo estaba atorado en un árbol. Le dijo el rayo: "Levanta mi hacha". El paisano respondió: "No puedo agarrar el fierro porque tiene lumbre". El rayo respondió: "Corta un palo para meter el fierro". El hombre cortó un palo y apretó el hacha y la alzó para arriba. El rayo le dijo: "Vete rápido porque va haber un viento y un aguacero muy fuerte dentro de un rato, pero no te espantes porque voy a echar lumbre" (Weitlaner, 1977: 97).

Entonces, "Rayo" como simple fenómeno pluvial también se presta como mediador: con él las aguas suceden al fuego. Asimismo, la advertencia que le hace "Rayo" al hombre no es gratuita; es claro que la acción ardiente de "Rayo" provoca dolor, hiere; es el precio por la obtención de la materia para la vida. De hecho, uno de los nombres de Chaak es Kolop, que quiere decir "el heridor" y que se otorgaba tanto

${ }^{14}$ Lo mismo sucede en otros mitos mayas acerca del origen del maíz; tal es el caso de los mames, los choles y los mopanes, donde es Chaac, en su manifestación de rayo, quien mediante la apertura de un agujero en la tierra logra sacar al maíz (véase Aviña Cerecer, 1994). 
al dios Chaak, que vivía en el centro y en medio del cielo, como a su representante en esta tierra "el señor rojo heridor" o también llamado "señor del sol rojo" (Thompson, 1987, p. 255).

Es claro que el sol y el fuego hieren, pero esta fuerza de la naturaleza es la misma que hace posible que el hombre y su medio se mantengan con vida. De hecho, es muy posible que entre los mayas sucediera en la época prehispánica lo mismo que entre los nahuas, entre quienes al hacha de cobre, que servía para las labores del campo, se le llamaba "sacerdote", tlamacazqui.

El inquisidor Ruiz de Alarcón nos explica claramente la analogía:

en quanto el sacerdote de ydolos que estos conocian, tenia por oficio sacrificar hiriendo, y por el effecto de herir da el mismo nombre del sacerdote o ministro del sacrificio a la hacha conque a de cortar (Ruiz de Alarcón, 1987: 156).

Entonces, hasta ahora es claro que la similitud entre los diversos elementos que entran en relación con "Rayo" lo hacen tanto por participar de su misma naturaleza caliente, como por ser parte del proceso de cortar y herir a la materia, función que permite sacar lo encubierto, lo esencial contenido. En tal sentido, esta labor de herir es relacionada por el maya como una acción masculina y celeste.

Al hombre dentro del cosmos le ha tocado el papel activo de provocar el dolor y la muerte, pero por la simple y sencilla razón de ser ésta la actividad que le permite vivir. Es claro que de ninguna manera esta concepción del dolor y el daño es igual a la de nuestra sociedad occidental; para el maya y muchos otros pueblos indígenas de México, el sufrimiento y la muerte no es más que el único medio para la liberación de lo esencial de la vida.

Los dioses y los santos han otorgado al hombre este poder de liberar mediante el dolor lo precioso contenido, empleando su propio cuerpo y el hacha o el pedernal punzocortante, pero también estos instrumentos los dieron al hombre para que se defendiera de los peligros que lo acechan constantemente. De hecho, en la conciencia indígena la defensa por la supervivencia es prácticamente lo mismo que la reproducción de la vida.

\section{3. "Rayo" es un regalo de poder}

En el universo mesomericano muchas de las fuerzas divinas sutiles, casi imperceptibles, que dominan a la materia dura son tan apetentes y codiciosas como cualquier ser humano.

La tierra es vista como un caimán que desea devorar hombres, o bien es un ser monstruoso que está lleno de mandíbulas voraces, ${ }^{15}$ o también es una mujer que desea copular con los hombres y cuando no encuentra amante puede llegar a causar problemas, como erupciones volcánicas y terremotos. ${ }^{16}$

En la selva lacandona los árboles están habitados por las Xtabay, mujeres jóvenes y hermosas que tientan al hombre para llevárselo al mundo de los muertos, especialmente a aquellos que están en penitencia sexual (Marion, 1993), esperando un don divino. Los enanitos de los bosques y las aguas, conocidos en toda Mesoamé-

\footnotetext{
${ }^{15}$ Véanse las representaciones escultóricas de la tierra entre los mexicas del periodo Posclásico, así como en varias láminas de los códices mayas, nahuas y mixtecas, donde se puede apreciar a la tierra como un enorme monstruo de enorme mandíbula voraz.

${ }^{16}$ Estas concepciones existen entre los mixes y los zoques, véase Báez, 1982. Cosa similar sucede entre los nahuas de la cuenca de México y el valle de Puebla, según Johana Broda, comunicación personal, mayo de 1994. Estudios de Cultura Maya. Vol. XXI, 2000 
rica y México con diversos nombres, pero que entre los mayas se llaman aluxo'ob, chaneques, ik'ales, etc., si no están trabajando con las lluvias y los vientos, también son capaces de hacer daño. ${ }^{17}$

Asimismo están los gigantes negros, seres masculinos de enorme poder que son bastante sanguinarios y habitan en volcanes y cuevas; ellos están al acecho de las riquezas de los hombres y también gustan de buscar lindas muchachas. ${ }^{18}$ Todas estas entidades son parte del universo maya, es decir, de la misma tierra y el cielo; por ende, el hombre, al defenderse de ellos, hiere a la tierra, pero a cambio obtiene vida para su pueblo y su territorio.

Para sacar la materia de vida de las cosas "Rayo" debe enfrentarse en una lucha frente a muchos seres anímicos de la naturaleza (incluyendo al ser humano); estos seres quieren apropiarse de lo vital para el buen desarrollo de la vida de una comunidad, pero los hombres cuen$\tan$ con la ayuda de "Rayo" para defenderse y, por lo tanto, también para permitir la libre circulación de las materias divinas esenciales.

"Rayo" es, entonces, el mismo instrumento con el que los hombres se defienden de las apetentes potencias y en general todos los individuos pueden ser considerados guerreros, pues las entidades divinas siempre están en busca de algún cautivo.

Hay individuos que son la manifestación misma de los dioses creadores y con el poder suficiente para especializarse en la lucha en contra de los seres hostiles; con ligeras variantes dialectales, hasta la fecha son conocidos en todo México con el nombre de naguales. Se les llama también Madre-Padre y hasta hace poco tiempo en varios pueblos mayas constituían una compleja red política de cuidado y sanción de las leyes de sus pueblos.

Entre los tojolabales, los tzeltales, los itzá, los zapotecos, los mixtecos, los zoques, los mixes y los totonacos, se establecen jararquías de poder en claras relaciones totémicas, de tal manera que la fuerza de las entidades atmosféricas se corresponde con el prestigio y poder de algún nagual. ${ }^{19}$

En la mayoría de los pueblos antes mencionados los poderes de mayor fuerza son el meteoro y el rayo. El primero es una bola de fuego que cruza el horizonte por debajo de la tierra; el otro es el nagual de mayor poder, el que vuela más alto. Entre todos los grupos mayas y los totonacas, el mayor poder lo tienen los viejos rayos. Entre los totonacas estos viejos pertenecen a una estructura política cuya sutilidad en los niveles del poder es tal que cada uno de los señores de los cuatro rumbos, los ya antes mencionados $\mathrm{Ba}$ $c a b o^{\prime} o b$ mayas, son los rayos, pero se dice que uno de ellos es el "Rayo" de más poder.

De igual manera, en el Popol Vub, según la traducción de Tedlock (1985, pp. 16-20), los rayos también están como sostenedores del mundo en cada uno de los cuatro rumbos, uniendo a la tierra con el cielo, permitiendo así el fluir de la materia divina temporal.

Entre los pueblos del istmo de Tehuantepec, los totonacos y los zapotecos, los mixtecos y los mixes, se piensa que el rayo de mayor poder es el negro; en cambio, entre los tojolabales, los choles, los yucatecos y los Itzá se considera que es el "Rayo verde".

A este respecto, es interesante notar que en el Códice Vaticano $B$ destaca un mapa cósmico con los cuatro señores de los puntos cardinales y el

${ }^{17}$ Véase un ejemplo de otra parte de Mesoamérica en Incháustegui, 1977.

${ }_{18}^{18}$ Respecto de estos personajes negros malignos entre los tzeltales, véase Hermitte, 1970; entre los tzutujiles de Guatemala, véase Orellano, 1975.

${ }^{19}$ Respecto a la naturaleza del complejo mesoamericano del nahualismo, véase Aviña Cerecer, 1993.

Estudios de Cultura Maya. Vol. XXI, 2000

Instituto de Investigaciones Filológicas/

Centro de Estudios Mayas, UNAM

ISSN: 0185-2574 
central. Los cinco tienen el hacha de "Rayo". Una de las figuras carece de nariz por completo, pero tiene un tocado con una calavera que en lugar de la nariz tiene un enorme cuchillo de pedernal, hecho que nos remite también al poder punzocortante de "Rayo" (figura 6).

Entre los cuicatecos, los tojolabales y los tzeltales, se dice que cada "Rayo", Madre-Padre, es un cuidador de una parte de su pueblo; más allá de sus límites de poder, ya no se hacen responsables de los habitantes de su comunidad. El hacha sigue siendo el arma con que estos naguales aplican la justicia. En los Códices Bor- gia, Vaticano B, el Dresde y el Madrid (estos dos últimos del área maya) aparecen varios Chaaks o Tlaloques empunando el hacha de "Rayo". En los casos del Borgia y del Madrid, son constantes los símbolos y los glifos del hacha sola. Seler interpreta esta hacha como el arma de la justicia solar. De hecho, son varias las referencias que tratan sobre el uso del rayo como instrumento del nagual.

Los tzutujiles de Guatemala poseen un buen ejemplo del uso de "Rayo" como instrumento de defensa del nagual; aquí se dice que había un volcán antropomorfo que había descendido

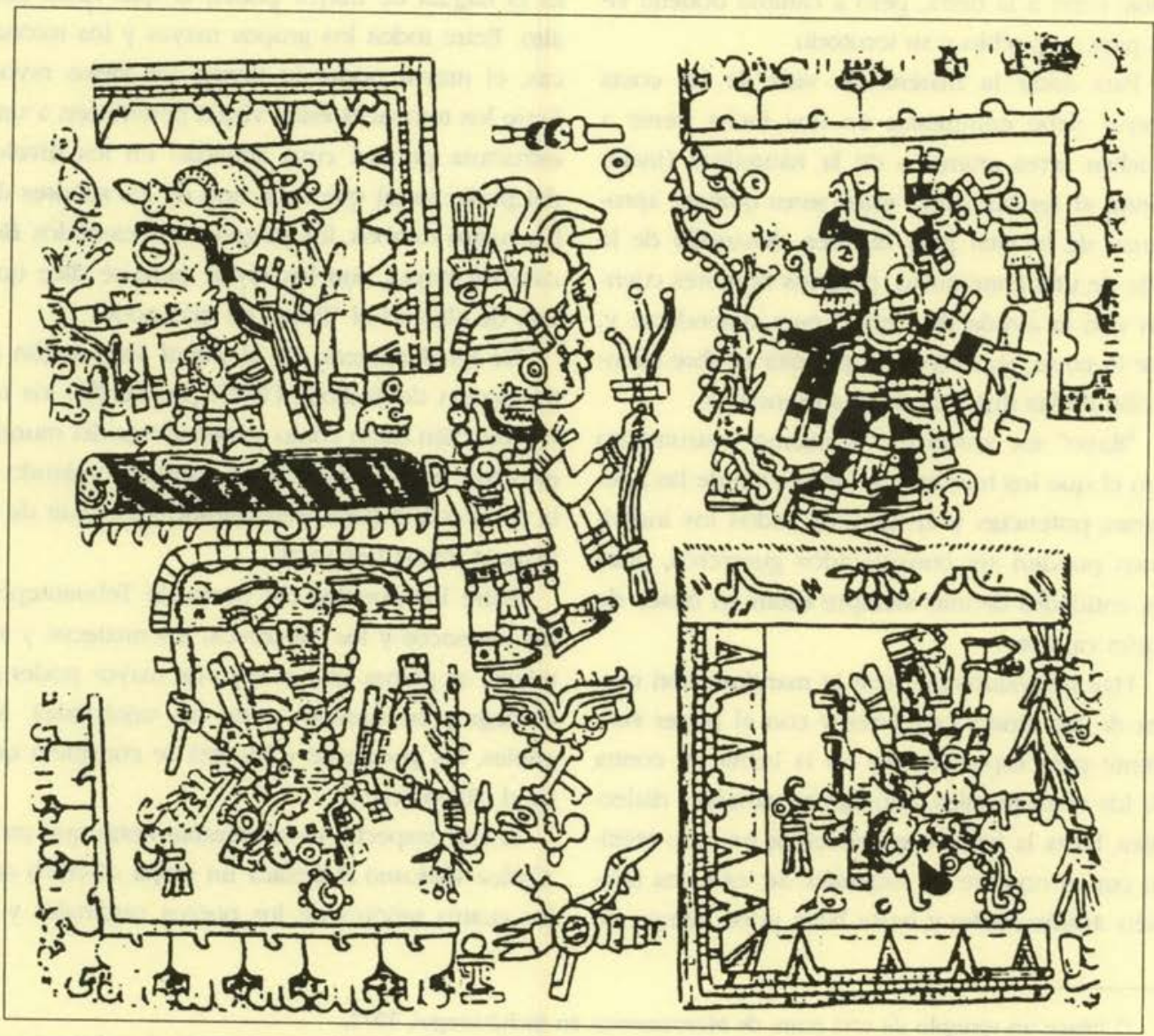

Figura 6. Lámina 69 del Códice Vaticano B donde aparece un tipo de tlaloques que sostienen en sus manos un hacha y un árbol con flores (tomado de Seler) 
hacia el pueblo; era un enorme negro o demonio y, entonces, las personas del pueblo en busca de amparo llamaron al Nagual Achá, Hombre Santo, que vivia en el pueblo de Santiago.

La gente creía que era muy poderoso y que era capaz de hacer milagros. Ellos le preguntaron si él podía dehacerse del hombre malo que vivía en el volcán... él dijo: Me desharé de aquel hombre, pero primero ustedes tienen que comprar velas e incienso para que yo pueda hacer un costumbre para llamar a Maximón; él es más grande que yo... El Nagual Achá le pidió: los principales que son tus hijos me pidieron que hagamos milagro juntos, para sacar a Itzel Bitnak, que vive en el volcán, porque él perderá a nuestros hijos que viven en el pueblo de Santiago.... Maximón contestó: Esto es lo que haremos. Yo me cambiaré en una mujer, en una muy linda mujer, la más hermosa de todo el mundo. Iré con el hombre y le diré que deseo ser su esposa. Le diré al hombre que salgamos a ver el sol y al cielo del Dios viviente.... Tú tienes el poder de hacer lluvia. Hazla sobre el volcán. Manda una tormenta con rayos de relámpago... Durante la fiesta del apóstol Santiago haremos el milagro de salvar al pueblo. [...] Maximón dijo a Nagual Achá: "Cuando nosotros dos estemos sentados, haz lluvia y golpea al hombre negro, directamente con un rayo, porque sólo eso lo dañará (Orellano, 1975: 864).

En esta historia es importante destacar el nombre del nagual: Nagual Achá; no pensamos que tal coincidencia con el nombre español de bacha sea casual, y menos si pensamos que esta historia fue recopilada no hace mucho tiempo. También es interesante la cadena que existe para lograr el triunfo: el nagual llama a Maximón; él a su vez se convierte en una mujer hermosa y además le pide al nagual que con sus poderes para hacer lluvia y relámpagos golpee con uno de éstos al hombre negro.
Maximón actualmente es un pequeño maniquí como de $1.20 \mathrm{~m}$ de altura; tiene una máscara de madera, un puro en la boca, sombrero oscuro de fieltro, un colorido ropaje de mascadas y saco oscuro. También tiene unos enormes y extraños zapatos, finamente pulidos. Esta vestimenta hace que los lugareños de Santiago se sientan orgullosos de la elegancia y finura de Maximón, ya que es demostración de su poder. ${ }^{20}$

La analogía entre Maximón y "Rayo", en su manifestación de Bolon Dz'akab, se acentúa al saber que en décadas pasadas, en 1953, se le informó a Mendelson, antropólogo de la Universidad de Chicago, que Maximón había sido creado después de nueve generaciones, y justamente éste es otro posible significado de Bolon $D z$ 'akab, ya que también se puede traducir como "Nueve Generaciones". Además recordemos que fray Diego de Landa en plena conquista de Yucatán pudo observar que Bolon Dz'akab era, al igual que Maximón y el cetro maniquí, "simplemente" un maniquí.

Con esta última relación finalizamos este trabajo, no sin antes concluir que mediante múltiples relaciones significativas "Rayo" aparece como un dios, instrumento de trabajo, arma letal e individuo. Todos estos elementos poseen (en menor o mayor medida) los más grandes poderes para lograr el contacto entre lo divino esencial contenido y lo duro visible contenedor, logro alcanzado gracias a su capacidad extremadamente caliente de cortar, penetrar y abrir. Su expresión más acabada durante la época prehispánica estaba en el hacha y en el cetro maniquí y en nuestros días, en una gran variedad de instrumentos punzocortantes, incluyendo a los naguales que encarnan esta fuerza de "Rayo"; así

${ }^{20}$ Observaciones realizadas por el autor en 1993 en Santiago Atitlán, Guatemala.

Estudios de Cultura Maya. Vol. XXI, 2000

Instituto de Investigaciones Filológicas/

Centro de Estudios Mayas, UNAM

ISSN: 0185-2574 
como en extraños personajes como el de Maximón.

"Rayo" es una potencia de extremo poder caliente que en la naturaleza cósmica media entre lo seco y lo húmedo, entre el fuego y el agua, entre lo cotidiano visible y lo esencial casi imperceptible, entre el hambre y el alimento, entre la enfermedad y la salud y, por ende, entre la guerra y la paz. Su fuerza se manifiesta tanto en una simple punzada ligeramente dolorosa, o en una tormenta desastrosa; al fin ambos hechos son una ruptura que derivará en la continuación del tiempo por la multiplicación de la vida.

\section{Bibliografia}

ARA, fray DOMINGo DE

1986 Vocabulario de lengua tzeldal según el orden de Copanaguastla, Mario $\mathrm{H}$. Ruz, editor, unam, Centro de Estudios Mayas, Fuentes para el Estudio de la Cultura Maya 4, México.

ASCHER, ROBERT

1961 "Analogy in Archeological Interpretation", Southwester Journal of Antbropology, vol. 17, Nueva York.

Augé, M.

1987 Símbolo, función e bistoria, Grijalbo, México.

Aviña Cerecer, Gustavo

1993 "El chamanismo y los nahuales", Ce Acátl, Revista de la Cultura de Anábuac, vol. 10, núm. 50, septiembre.

1994 El dios K: Rayo de vida y muerte, tesis de licenciatura en arqueología, Escuela Nacional de Antropología e Historia, INAH, México, 190 pp. +65 ilustraciones.

1997 "El caso de doña Pragedis en la lógica del Rayo", en Los graniceros, los que trabajan con el tiempo, Instituto Mexiquense de Cultura/ unam, México.

BÁez, Jorge FéLux

1982 "Cuando ardió la tierra y se quemó el cie-

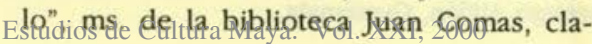
Instituto de Investigaciones Filológicas/

Centro de Estudios Mayas, UNAM ve: Etn9BCODA, Instituto de Investigaciones Antropológicas, unam, México.

BARrera VÁsquez, AlFredo, coord.

1980 Diccionario Maya Cordemex, Ediciones Cordemex, Mérida, México.

- y Silvia Rendón, traductores

1972 El libro de los libros del Chilam Balam, FCE, México.

1972 Códice Vaticano B, Akademische Druck, Austria.

\section{Cbilam Balam}

1972 El libro de los libros del Chilam Balam, trad. de Alfredo Barrera Vásquez, FCE, México.

COE, Michael.

1978 The Lords of the Underworld: Master Pieces of Classic Maya Ceramics, Princeton University, Princeton.

Coggins, Clemency

1987 "New Fire at Chichen Itza, México", Memorias del Primer Coloquio Internacional de Mayistas, Centro de Estudios Mayas, unam, México.

1988 "The Manikin Scepter: Emblem of Linage", Estudios de Cultura Maya, vol. xvı, Centro de Estudios Mayas, unam, México.

Garza, Mercedes de LA

1984 El universo sagrado de la serpiente entre los mayas, Centro de Estudios Mayas, UNam, México.

1990 Sueño y alucinación en el mundo maya y nábuatl, Centro de Estudios Mayas, unam, México.

GREenE, R. M.

1985 The Sculpture of Palenque, vol. III, The Late Building of the Palace, Princeton University Press, Princeton.

HERMITTE, M. ESTHER

1970 Poder sobrenatural y control social, Instituto Nacional Indigenista, México.

HODDER, I.

1988 Interpretaciones en arqueología, Crítica, Barcelona.

InChíustegul, CARLos

1977 Relatos del mundo mágico mazateco, SEP/ INAH, México.

ICHON, A.

1973 La religión de los totonacos de la sierra, Instituto Nacional Indigenista, México.

KERR, J.

1989 The Maya Vase Book, 2 volúmenes, Kerr Associates, Nueva York. 
KosIK, KAREL.

1982 Dialéctica de lo concreto, Grijalbo, México. La Jornada Semanal

1994 En La Jornada, 16 de enero, México.

LANDA, fray DIEGo DE

1986 Relación de las cosas de Yucatân, Porrúa, México.

LEACH, E.

1977 Cultura y comunicación, Siglo XXI, Madrid.

León Portilla, Miguel

1984 Literaturas de Mesoamérica, SEP, México.

Lévi-Strauss, Claude

1984 El pensamiento salvaje, FCE, México.

1986 El totemismo en la actualidad, FCE, México.

1992 Antropología estructural, Paidós, Barcelona.

LÓPEZ Austin, AlFredo

1989 Cuerpo bumano e ideología. Las concepciones de los antiguos mayas, vol. 1, Instituto de Investigaciones Antropológicas, unam, México.

1990 Los mitos del tlacuacbe, Alianza, México.

1993 "El árbol cósmico en la tradición mesoamericana", Iicbiko Intercultural, núm. 5, junio, Japón.

MARION, Marie Odile

1993 Le pouvoir du la fille de la Lune, tesis de doctorado, trad. de Nathalie Ragot, EHEss, París.

Navarrete, Carlos

1974 "La religión de los antiguos chiapanecas, México", en Anales de Antropología, volumen XI, Instituto de Investigaciones Antropológicas, unam, México.

Norman, G.

1973 Izapa Sculpture, Papers of The New Archaeological Fundation 30, Provo.

OrelLANo, SANDRA

1975 "Folk Literature of Tzutujil Maya", Antropos, 70.

OKoshi, Tsubasa

1992 Los canules, análisis etnobistórico del Códice Calkini, tesis de doctorado, Facultad de Filosofía y Letras, unam, México.

Ortiz, Fernando

1984 El buracán, su mitología y sus simbolos, FCE, México.

\section{Popol Vub}

1974 Trad. de Adrián Recinos, FCE, México.

PANOWSKY, E.

1972 Estudios sobre iconologia, Alianza, Madrid.

Robicsek, Francis

1979 "The Mytological Identity of God K", en Merle Greene Roberson y D. C. Jeffers, eds., Tercera Mesa Redonda de Palenque, vol. IV, Precolumbian Art Research Center, Monterey, California.

Ruiz de Alarcón, H.

1987 Tratado de las supersticiones y costumbres gentilicias que boy viven entre los indios, en Varios, El alma encantada, FCE, México.

SChele, Linda, y M. E. Miller

1992 The Blood of Kings, Thames and Hudson, Londres.

Schumann, Otro

1973 La lengua chol de Tila Cbiapas, Centro de Estudios Mayas, unam, México, Cuadernos, 8.

SPINDEN, Herbert

1992 A Study of Maya Art, Dover, Nueva York.

Taube, Karl A.

1992 The Major Gods of Ancient Yucatan, Dumbarton Oaks, Washington, D.C.

TedLock, D.

1985 Popol Vub, Simon \& Schuster, Nueva York.

Tномpson, J. E. S.

1987 Historia y religión de los mayas, Siglo XXI, México.

1943 "Maya Epigraphy: A Cycle of 819 Days", Notes in Middle American Archaeology and Etbnology, 30 de octubre, Carnegie Institution of Washington, Washington, D.C.

VILLA Rojas, ALFonso

1985 Estudios etnológicos de los mayas, unam, México.

Weithaner, R. J.

1977 Relatos, mitos y leyendas de la Cbinantla, Instituto Nacional Indigenista, México.

WITtGenstein, L.

1997 Observaciones filosóficas, trad. de Alejandro Tomassini Bassols, cotejada contra el texto alemán por Marlene Zinn, Instituto de Investigaciones Filosóficas, UNaM, Filosofia Contemporánea, México. 